\title{
Effect of Sn Addition on the Mechanical and Electrical Properties of $\mathrm{Cu}-15 \% \mathrm{Cr}$ In-Situ Composites
}

\author{
Shigeki Skai ${ }^{1}$, Hirowo G. Suzuki ${ }^{2}$,, Kuniteru Mihara ${ }^{1}$ and Jusheng $\mathrm{Ma}^{3}$ \\ ${ }^{1}$ THE FURUKAWA ELECTRIC CO. LTD., Nikko 321-1493, Japan \\ ${ }^{2}$ Japan Science Promotion Society, Tokyo 102-8471, Japan \\ ${ }^{3}$ Tsinghua University, Beijing 100084, P.R. China
}

Effect of Sn addition on the mechanical and electrical properties of $\mathrm{Cu}-15 \% \mathrm{Cr}$ in-situ composites has been studied. The addition of $0.1 \% \mathrm{Sn}$ is effective for the solid solution hardening. Accumulation of high density of dislocations and development of banding structure by cold drawing give the increment of tensile strength. The precipitation of $\mathrm{Cr}$ in cupper matrix was accelerated and distinct secondary hardening occurs after cold rolling and aging treatment. It was found that the tensile strength of $1100 \mathrm{MPa}$ with electrical conductivity of 70\%IACS were attained in the $\mathrm{Cu}-15 \% \mathrm{Cr}-0.1 \% \mathrm{Sn}$ by the optimization of thermomechanical processing.

(Received July 8, 2002; Accepted December 6, 2002)

Keywords: Cu alloy, high strength, electrical conductivity, $\mathrm{Cr}$, composite

\section{Introduction}

$\mathrm{Cu}$ base in-situ composites have superior characteristics of high strength with high electrical conductivity (EC). The alloys having the tensile strength of more than $1000 \mathrm{MPa}$ with EC of more than 70\%IACS have been developed. In-situ composites mean that the alloying elements having small solubility solidify dendritically by themselves in the $\mathrm{Cu}$ matrix during cooling from the melt and exist as a fiber or ribbon-like second phase in the $\mathrm{Cu}$ matrix after hot or cold rolling. Extensive studies have been carried out on $\mathrm{Cu}$ base in-situ composites such as $\mathrm{Cu}-(\mathrm{Fe}, \mathrm{Cr}, \mathrm{Si}),{ }^{1)}-\mathrm{Fe},{ }^{2-4)}-\mathrm{Mo},{ }^{2,5)}$ $-\mathrm{Ag},{ }^{6-9)}-\mathrm{Cr}^{2,3,10)}$ Among them, $\mathrm{Cu}-15 \% \mathrm{Ag}^{8,9)}$ alloy is the best combination of strength and $\mathrm{EC}$ and thus in practical use for coil of strong magnetic generator except production cost. We have invented economical $\mathrm{Cu}-15 \% \mathrm{Cr}(15 \mathrm{Cr})$ binary alloy $^{11)}$ (strength level is $900 \mathrm{MPa}$ and EC of $75 \%$ IACS and $\mathrm{Cu}-15 \% \mathrm{Cr}-0.15 \% \mathrm{Zr}(15 \mathrm{CZ})$ and/or $0.2 \% \mathrm{Ti}$ (15CT) ternary alloys, ${ }^{12,13)}$ which have the strength level of $1150 \mathrm{MPa}$ and EC of 70\%IACS. Very fine precipitates of $\mathrm{Cr}, \mathrm{Zr}$ and/or Ti were accelerated by the cold rolling and aging treatment. One of the weak point is that $\mathrm{Ti}$ and $\mathrm{Zr}$ are very active elements, so some difficulty exist in the melting process.

In this report, the effect of alloying of Sn is studied aiming to get high strength with high EC and lower production cost. $\mathrm{Sn}$ is a solid solution hardener of $\mathrm{Cu}$ matrix and is very popular element for dilute $\mathrm{Cu}$ alloys, but no research on the behavior in the $15 \mathrm{Cr}$ in-situ composites.

\section{Experimental Procedure}

Four nine level of pure $\mathrm{Cu}, \mathrm{Cr}, \mathrm{Fe}$ blocks, and $\mathrm{Cu}-30 \% \mathrm{Sn}$ master alloy were prepared and vacuum induction melted under the pressure of $2 \times 10^{-2} \mathrm{~Pa}$. The melting temperature is $1800 \mathrm{~K}$. The size of $45 \times 45 \times 120 \mathrm{~mm}^{3}$ and $2 \mathrm{~kg}$ weighing ingots were produced. The chemical compositions of these alloys were tabulated in Table $1.15 \mathrm{C} 1 \mathrm{~S}$ denotes $\mathrm{Cu}-15 \% \mathrm{Cr}-$

${ }^{*}$ Present address: Tsinghua University, Beijing 100084, P.R. China.
Table 1 Chemical compositions of the alloys.

\begin{tabular}{ccccccc}
\hline & \multicolumn{1}{c}{} & & \multicolumn{2}{c}{ (mass\%) } \\
\hline $15 \mathrm{Cr} 1 \mathrm{~S}$ & 15.02 & 0.095 & 0.002 & $<0.001$ & $<0.001$ & Bal. \\
$15 \mathrm{C} 5 \mathrm{~S}$ & 15.05 & 0.498 & 0.002 & $<0.001$ & $<0.001$ & Bal. \\
\hline
\end{tabular}

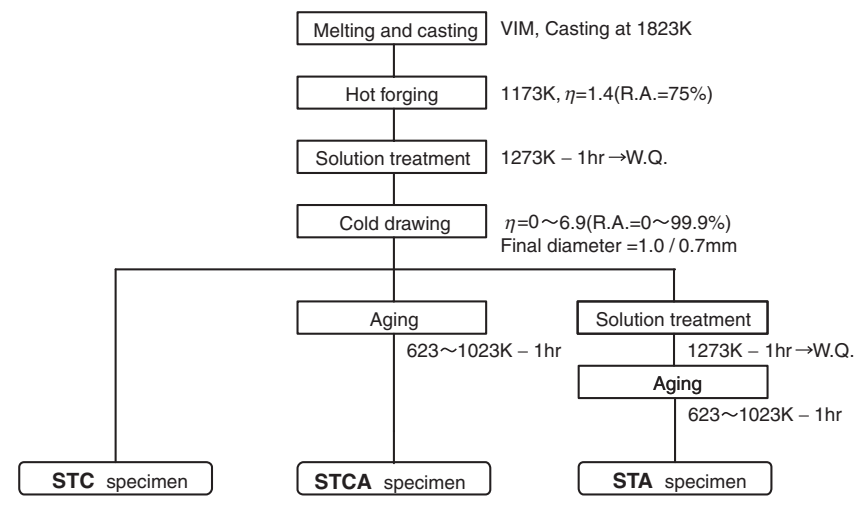

Fig. 1 Schematic presentation of thermomechanical processing of $\mathrm{Cu}-\mathrm{Cr}$ in-situ composites.

$0.1 \% \mathrm{Sn}$ and $15 \mathrm{C} 5 \mathrm{~S}$ means $\mathrm{Cu}-15 \% \mathrm{Cr}-0.5 \% \mathrm{Sn}$. Reference alloys are called as $15 \mathrm{Cr}(\mathrm{Cu}-15 \% \mathrm{Cr})$. The procedure for the sample preparation was schematically shown in Fig. 1. The ingots were hot-forged at $1173 \mathrm{~K}$ with the reduction of $\eta=$ 1.4 to break down the cast structure and then solution treated at $1273 \mathrm{~K}$ for $1 \mathrm{~h}$, followed by water quenching to room temperature. The test coupons were sliced into a cross section of $400 \mathrm{~mm}^{2}$ to $1 \mathrm{~mm}^{2}$ and cold rolled using rolling mill and roller dice to produce wire specimens having various drawing strain $\eta$ of 0 to 6.9. After cold rolling, wire specimens were subjected to the aging treatment in the range from $623 \mathrm{~K}$ to $1023 \mathrm{~K}$ for $1 \mathrm{~h}$ (STCA specimens, solution treatment-cold rolling-aging). STC indicates the specimens subjected to the solution treatment and cold rolling. STA specimens mean solution treatment and direct aging. 
Microstructural examination was done by optical microscopy, SEM (JSM-6100) and TEM (JEM-2000FX) attached by EDX analyzer. Thin foils were prepared by twin jet polishing using an electrolyte of phosphoric acid plus methanol. Thin foils were electrolytically polished under the condition of liquid nitrogen temperature at $10 \mathrm{~V}$ and $0.1 \mathrm{~A}$ and followed by ion milling for $10 \mathrm{~min}$ at $293 \mathrm{~K}$ and $3 \mathrm{kV}$. EC of wire specimens was measured by four point terminal method in a thermostatic bath at $293 \mathrm{~K}$. It was then calculated as an average of two measurements with the polarity reversed on the terminals $200 \mathrm{~mm}$ apart.

\section{Experimental Results}

\subsection{Microstructure}

Cast structure consists of $\mathrm{Cr}$ dendrite and $\mathrm{Cu}$ matrix (Fig. 2). This $\mathrm{Cr}$ dendrite was extracted by chemical etching with $\mathrm{HNO}_{3}$ and is chemically analyzed as shown in Table 2. Half content of the alloying $\mathrm{Sn}$ is partitioned into $\mathrm{Cr}$ phase in $15 \mathrm{C} 1 \mathrm{~S}$ and $31 \%$ of $\mathrm{Sn}$ is into Cr phase in $15 \mathrm{C} 5 \mathrm{~S}$ alloy. It is also noted that impurity elements such as $\mathrm{Fe}$ and $\mathrm{C}$ are scavenged into $\mathrm{Cr}$ phase. Microstructural change by cold drawing is shown in Fig. 3. Dendritic $\mathrm{Cr}$ deforms into rolling direction and fine lamellar structure is formed after heavy deformation such as $\eta=6.37$, resulting in the two phase composite.

\subsection{Cold drawing}

Figure 4 shows both the $\mathrm{Cr}$ lamellar spacing $(d)$ and thickness of Cr lamellar $(t)$ against cold drawing strain. The measurement was done at the cross section parallel to the

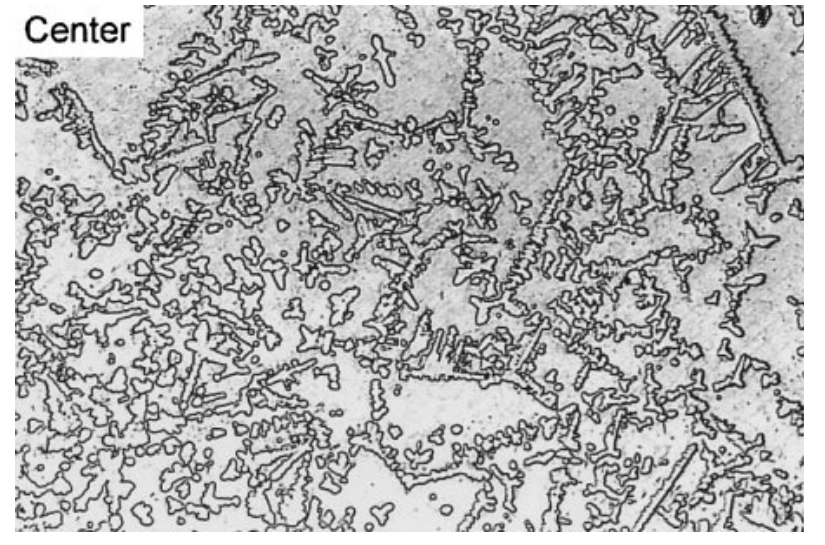

Fig. 2 Cast structure of $\mathrm{Cu}-15 \% \mathrm{Cr}-0.1 \% \mathrm{Sn}$ alloy.

Table 2 Chemical compositions of $\mathrm{Cr}$ phase extracted from the $\mathrm{Cu}-\mathrm{Cr}-\mathrm{Sn}$ alloys.

\begin{tabular}{ccccccc}
\hline & \multicolumn{1}{c}{ (mass\%) } \\
\hline $15 \mathrm{Cn} 1 \mathrm{~S}$ & 0.31 & 0.27 & 0.012 & 0.012 & $<0.001$ & $\mathrm{Cr}$ \\
$15 \mathrm{C} 5 \mathrm{~S}$ & 1.02 & 0.32 & 0.011 & 0.007 & 0.002 & Bal. \\
\hline
\end{tabular}

rolling direction. Maximum drawing strain was $\eta=6.37$ and $d$ was $0.8 \mu \mathrm{m}$, where fracture occurred by shearing the $\mathrm{Cr}$ lamellar. The relation of $t$ and $d$ with $\eta$ is derived by the least square fitting method as follows; $t=3.25 \exp (-0.29 \eta), d=$ $12.04 \exp (-0.45 \eta)$ for $15 \mathrm{C} 5 \mathrm{~S}$ and $t=7.58 \exp (-0.42 \eta)$, $d=7.18 \exp (-0.31 \eta)$ for $15 \mathrm{C} 1 \mathrm{~S}$. The square shape data in
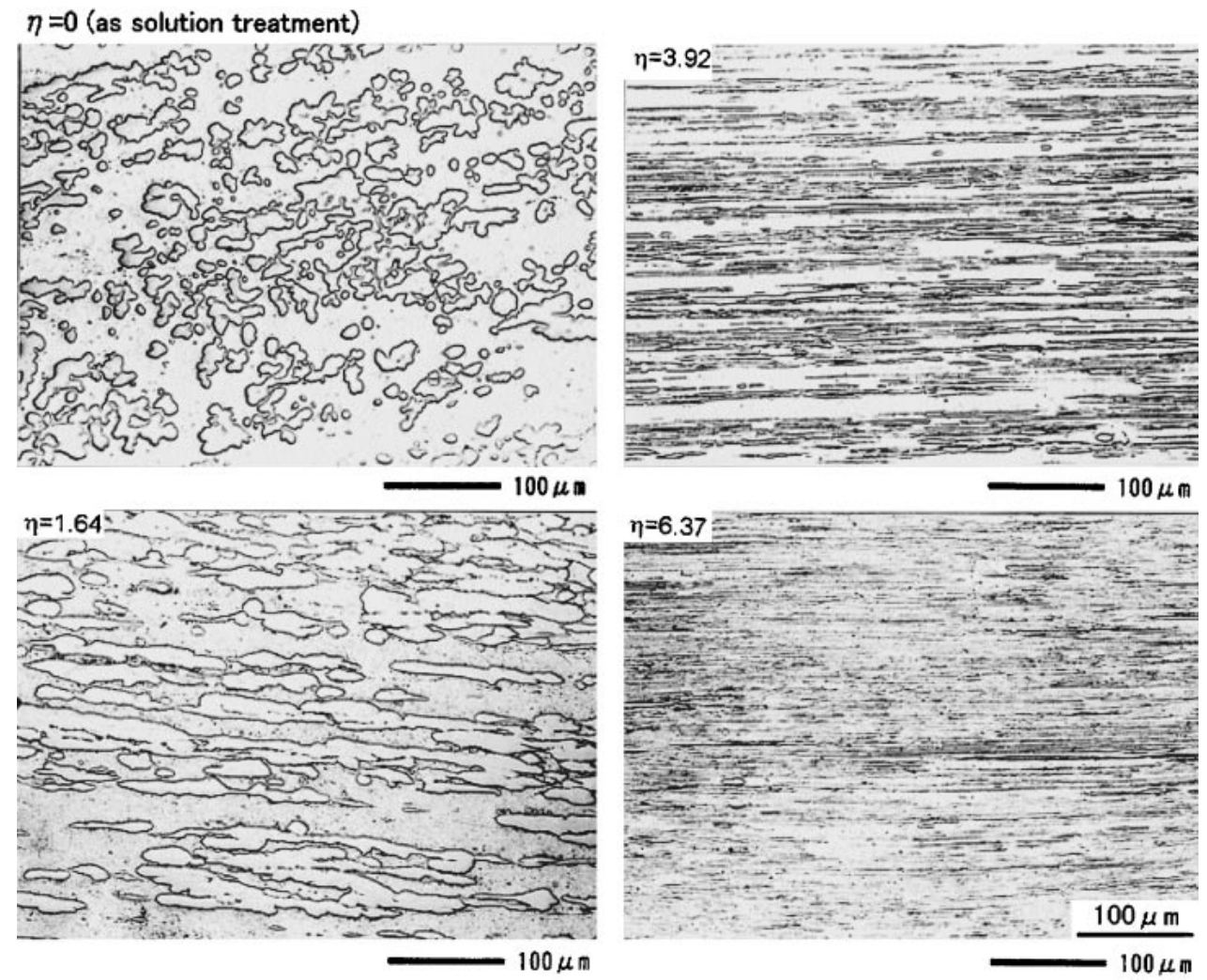

Fig. 3 Microstructural changes by cold drawing in $\mathrm{Cu}-15 \% \mathrm{Cr}-0.1 \% \mathrm{Sn}$ alloy. 


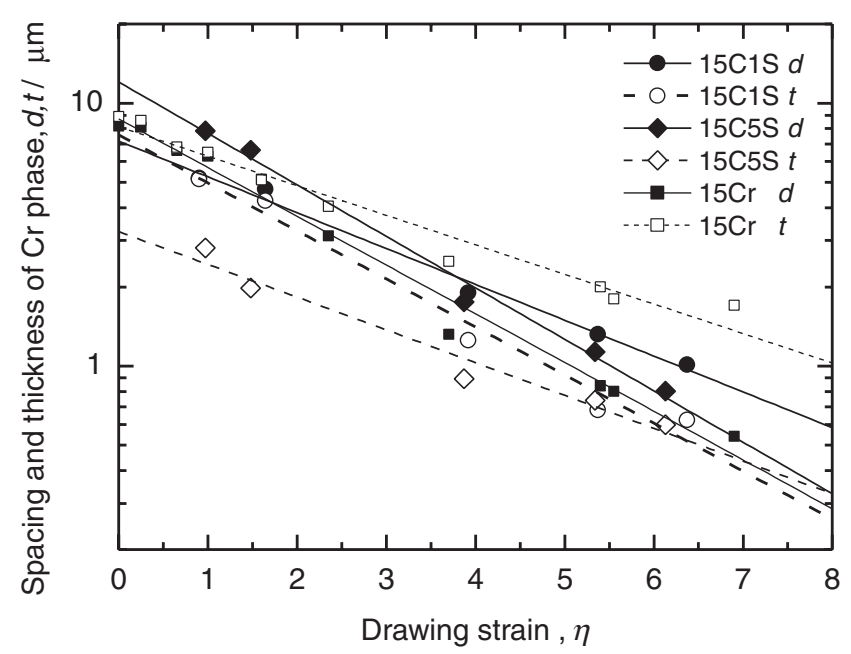

Fig. 4 Effect of drawing strain on spacing $(d)$ and thickness $(t)$ of $\mathrm{Cr}$ phase in $\mathrm{Cu}-15 \% \mathrm{Cr}-0.1 \% \mathrm{Sn}(15 \mathrm{C} 1 \mathrm{~S}), \mathrm{Cu}-15 \% \mathrm{Cr}-0.5 \% \mathrm{Sn}(15 \mathrm{C} 5 \mathrm{~S})$ and $\mathrm{Cu}-$ $15 \% \mathrm{Cr}(15 \mathrm{Cr})$.

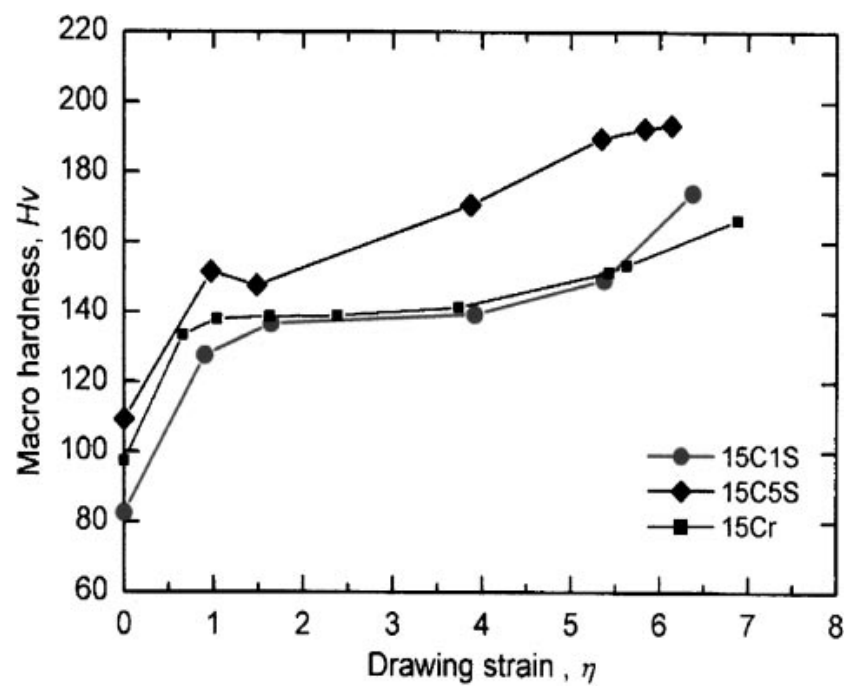

Fig. 5 Effect of drawing strain on macrohardness in 15C1S, 15C5S and $15 \mathrm{Cr}$.

this figure is for $15 \mathrm{Cr}$, which indicates the lamellar spacing of two Sn doped alloys is coarser than that of binary alloy. One reason for this is due to the initial coarse dendrite structure of Sn doped alloys.

Figure 5 shows the relation between macrohardness and drawing strain. Hardness shows sharp increase in the early stage of straining and then gradually increases with drawing strain until $\eta=6.37$ (maximum strain). The change of tensile strength was shown in Fig. 6. This result shows more clearly the beneficial effect of $\mathrm{Sn}$ addition. The increase of the strength is evident even in $15 \mathrm{C} 1 \mathrm{~S}$, low Sn addition. The maximum strength attained is $1000 \mathrm{MPa}$ in $15 \mathrm{C} 1 \mathrm{~S}$. $0.2 \% \mathrm{PS}$ and tensile strength were plotted as a function of lamellar spacing $d$ (Fig. 7), which shows the linear relationship between strength and $d^{-1 / 2}$ suggesting Hall-Petch like relationship exists in this cold rolled alloys as already discussed. $^{11-13)}$

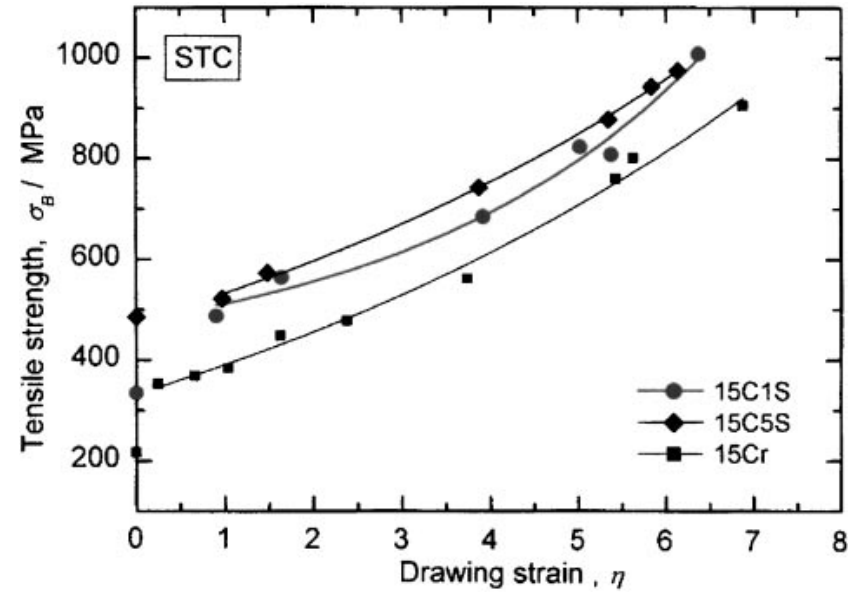

Fig. 6 Relation between tensile strength and drawing strain in $15 \mathrm{C} 1 \mathrm{~S}$, $15 \mathrm{C} 5 \mathrm{~S}$ and $15 \mathrm{Cr}$.

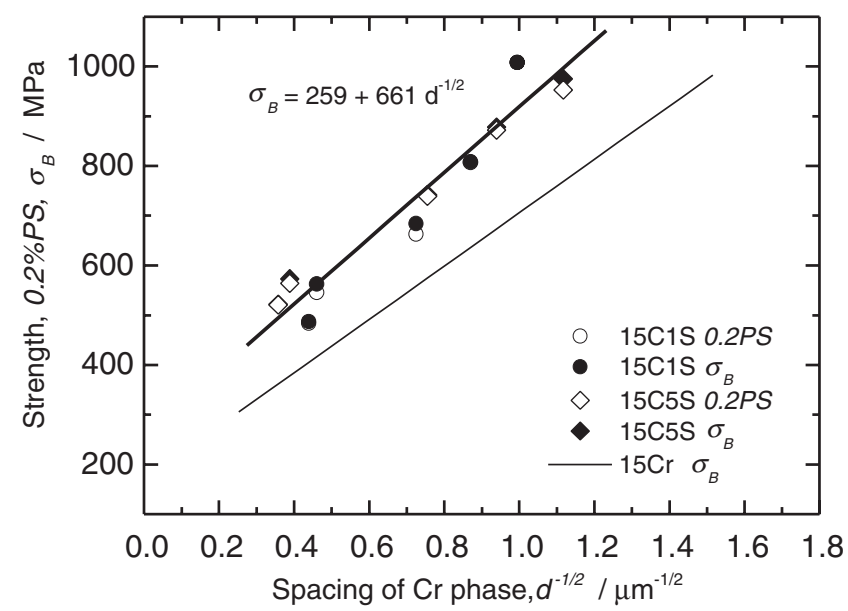

Fig. 7 Relation between $0.2 \% \mathrm{PS}$, tensile strength and spacing of $\mathrm{Cr}, d$, in the cold drawn $15 \mathrm{C} 1 \mathrm{~S}, 15 \mathrm{C} 5 \mathrm{~S}$ and $15 \mathrm{Cr}$.

\subsection{Effect of aging}

Figure 8 shows the hardness change with aging temperature, where open circle and open square data are STA treated ones and solid circle and solid square data are from the STCA (cold rolled and aged). Both results of STA and STCA clearly show that there exists the secondary hardening due to the precipitation and peak temperature lies around $750 \mathrm{~K}$. On the other hand, in the STCA process, peak hardness is shifted to lower temperature around $700 \mathrm{~K}$ and peak hardness reached to $200 \mathrm{Hv}$ due to the acceleration of precipitation on the defects introduced by cold drawing. It is evident from these data that the addition of $\mathrm{Sn}$ to $\mathrm{Cu}-15 \% \mathrm{Cr}$ is effective to increase the hardness. The result for the tensile strength against aging temperature is shown in Fig. 9. These values are unexpectedly low ones in view from the hardness value. The actual strength level can be higher than this. This point will be discussed later.

The data for EC against aging temperature is shown in Fig. 10. It is noted that EC recovers from the beginning of aging treatment and increases with the increment of aging temperature, reaching maximum around 800 to $900 \mathrm{~K}$ and then goes down again. This behavior corresponds to the 


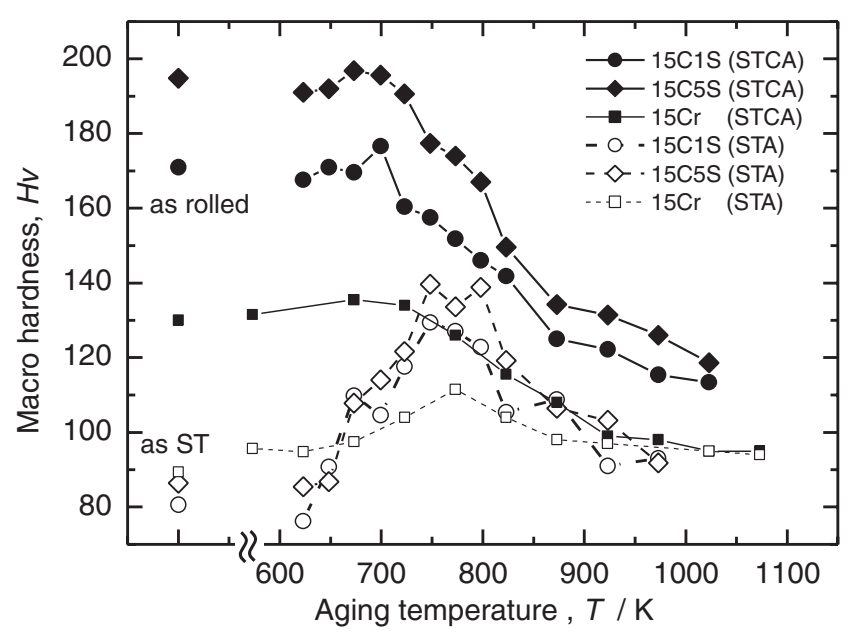

Fig. 8 Effect of aging temperature on the macrohardness of STCA specimens in $15 \mathrm{C} 1 \mathrm{~S}, 15 \mathrm{C} 5 \mathrm{~S}$ and $15 \mathrm{Cr}$. Drawing strain is $\eta=5.3$ for $15 \mathrm{C} 1 \mathrm{~S}, 15 \mathrm{C} 5 \mathrm{~S}$ and $\eta=5$ for $15 \mathrm{Cr}$.

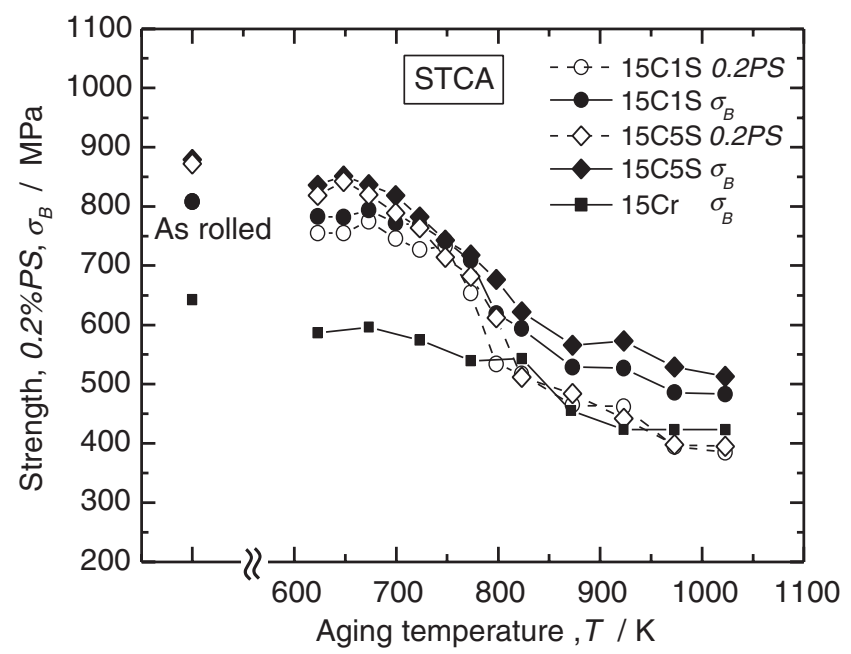

Fig. 9 Effect of aging temperature on $0.2 \% \mathrm{PS}$ and tensile strength of STCA specimens in $15 \mathrm{C} 1 \mathrm{~S}, 15 \mathrm{C} 5 \mathrm{~S}$ and $15 \mathrm{Cr}$. Drawing strain is $\eta=5.3$ for $15 \mathrm{C} 1 \mathrm{~S}, 15 \mathrm{C} 5 \mathrm{~S}$ and $\eta=5$ for $15 \mathrm{Cr}$.

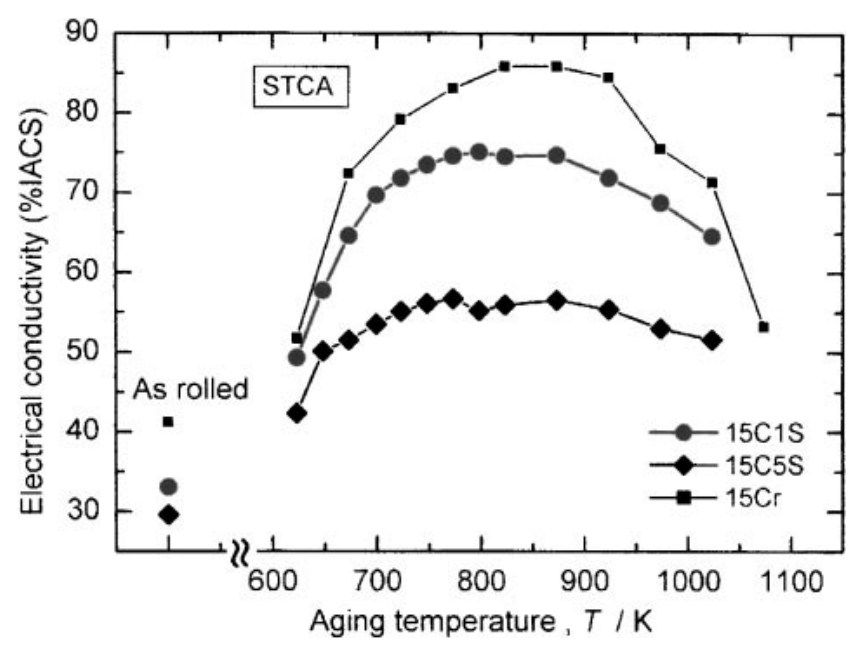

Fig. 10 Effect of aging temperature on the electrical conductivity of STCA specimens in $15 \mathrm{C} 1 \mathrm{~S}, 15 \mathrm{C} 5 \mathrm{~S}$ and $15 \mathrm{Cr}$. Drawing strain is $\eta=5.3$ for $15 \mathrm{C} 1 \mathrm{~S}, 15 \mathrm{C} 5 \mathrm{~S}$ and $\eta=5$ for $15 \mathrm{Cr}$. precipitation and re-solutioning of $\mathrm{Cr}$ precipitates in $\mathrm{Cu}$ matrix and quite similar characteristics with those of already reported ones. ${ }^{14,15)}$ It is noted that aging temperature giving the EC maximum is the overaging region, where the strength goes down.

Microstructure at the aging temperature corresponding to the peak hardness, $698 \mathrm{~K}$, high density of dislocations (Fig. 11, top left), banded structure (Fig. 11, top right) and fine precipitates on the dislocations and in the matrix (Fig. 11 bottom left) were observed. These precipitates were determined as Cr by EDS in-situ analysis and there was no signal corresponds to Sn (Fig. 11, bottom right). Figure 12 is the TEM micrographs taken after being aged at $873 \mathrm{~K}$ for $1 \mathrm{~h}$, at the stage of overaged condition. Top left of Fig. 12 is low magnification. Top right and bottom left figures are high magnifications showing $\mathrm{Cr}$ precipitates in the $\mathrm{Cu}$ matrix and bottom right is the result of EDX analysis showing $\mathrm{Cr}$ signal from $\mathrm{Cr}$ precipitates.

\section{Discussion}

\subsection{Effect of $\mathrm{Sn}$ addition to $\mathrm{Cu}-15 \% \mathrm{Cr}$ in-situ composite}

As was expected from the conventional $\mathrm{Cu}-\mathrm{Sn}$ alloys (bronze), the addition of $\mathrm{Sn}$ in $\mathrm{Cu}-15 \mathrm{Cr}$ in-situ composites is effective to increase the strength of cold rolled as well as aged specimens. In the cold rolled specimens, solid solution of $\mathrm{Sn}$ retards the dynamic recrystallization of $\mathrm{Cu}$ matrix, leading to the high density of dislocations as shown in Fig. 11. Because the strength of cold rolled specimens follows Hall-Petch type equation, it is important to refine the Cr lamellar spacing by cold rolling. It was not realized in this experiment, but if the cast structure becomes finer, the lamellar spacing can be refined more. Also, coarse dendritic structure gives rise to the heterogeneity of rolling strain leading to the localization of strain resulted in the limitation of cold drawability.

In the aged specimens, it is quite clear from Fig. 8 that the precipitation of $\mathrm{Cr}$ in $\mathrm{Cu}$ is accelerated by the addition of $\mathrm{Sn}$. The precipitates such as $\mathrm{Cu}_{3} \mathrm{Sn}$ ( $\varepsilon$ phase) or $\mathrm{Cu}_{41} \mathrm{Sn}_{11}(\delta$ phase) was not detected because the solubility of $\mathrm{Sn}$ is large even in the low temperature (ex, $\mathrm{Sn}$ solubility in $\mathrm{Cu}$ is 11 mass $\%$ at $573 \mathrm{~K}^{16)}$ ). Therefore, it is suggested that the solubility of $\mathrm{Cr}$ in cupper matrix at lower temperature is limited by $\mathrm{Sn}$ addition which promotes the precipitation of $\mathrm{Cr}$. Higher content of Sn gives higher strength for the cold rolled and aged specimens, but EC decreases to some extent. So, it is preferable to add 0.1 to 0.2 mass \% of $\mathrm{Sn}$ in the $\mathrm{Cu}-$ $15 \% \mathrm{Cr}$ in-situ composites to get high strength with high EC.

\subsection{The strengthening mechanism}

The factors governing the overall strengthening are high density of dislocations, banded structure of cupper matrix, spacing of $\mathrm{Cr}$ lamellar phase, which acts as barrier for the dislocation motion, and precipitation of $\mathrm{Cr}$ in the cupper matrix. Sun et al. ${ }^{17)}$ has discussed in details on the strengthening of the $\mathrm{Cu}-\mathrm{Cr}$ in-situ composites and derived the following equation as the model of strengthening. 


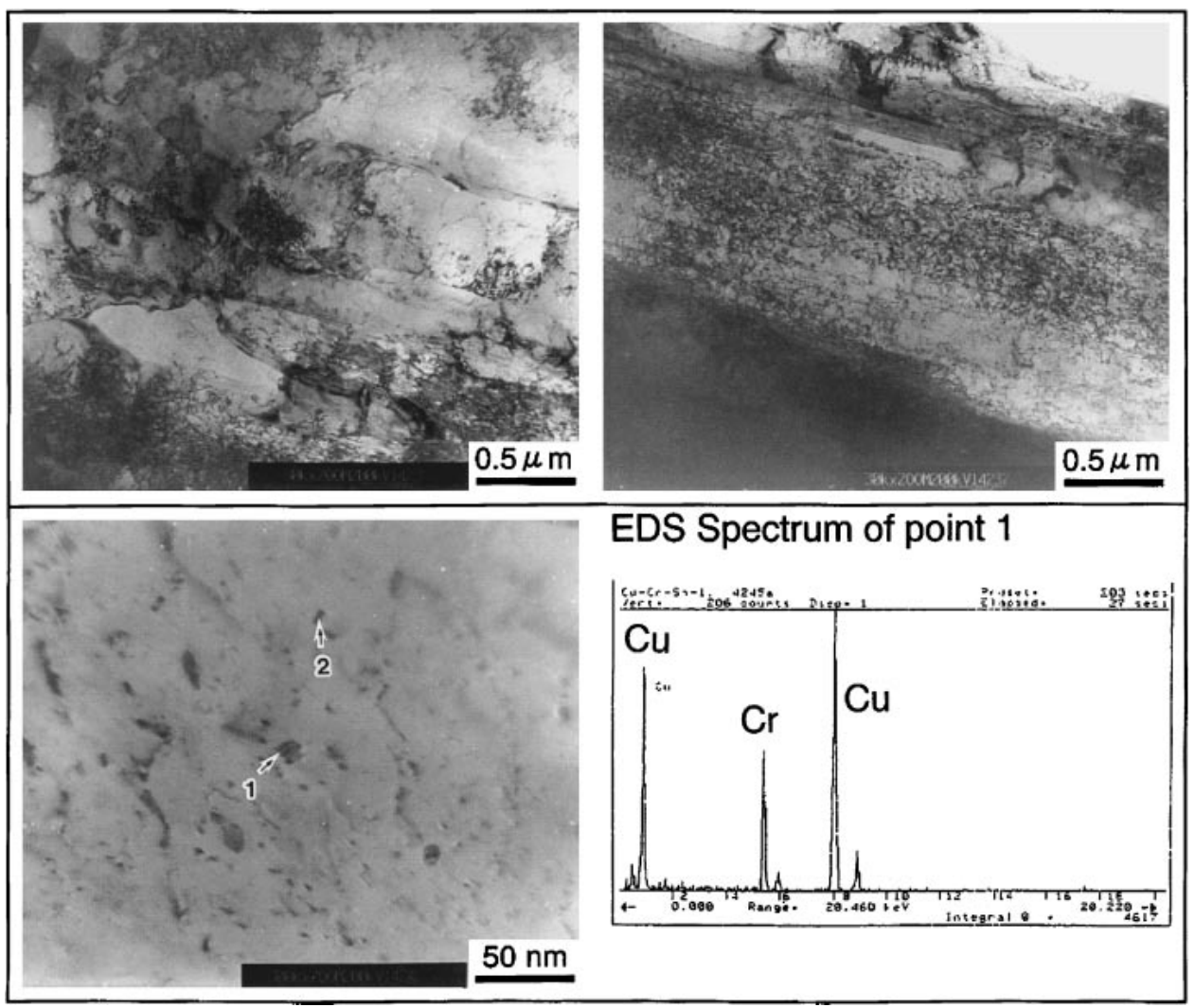

Fig. 11 TEM bright field images and EDS spectrum of the STCA specimen in $15 \mathrm{C} 1 \mathrm{~S}$ alloy. $\eta=5.3$ and aged at $698 \mathrm{~K}$ for $1 \mathrm{~h}$ (peak hardness condition).

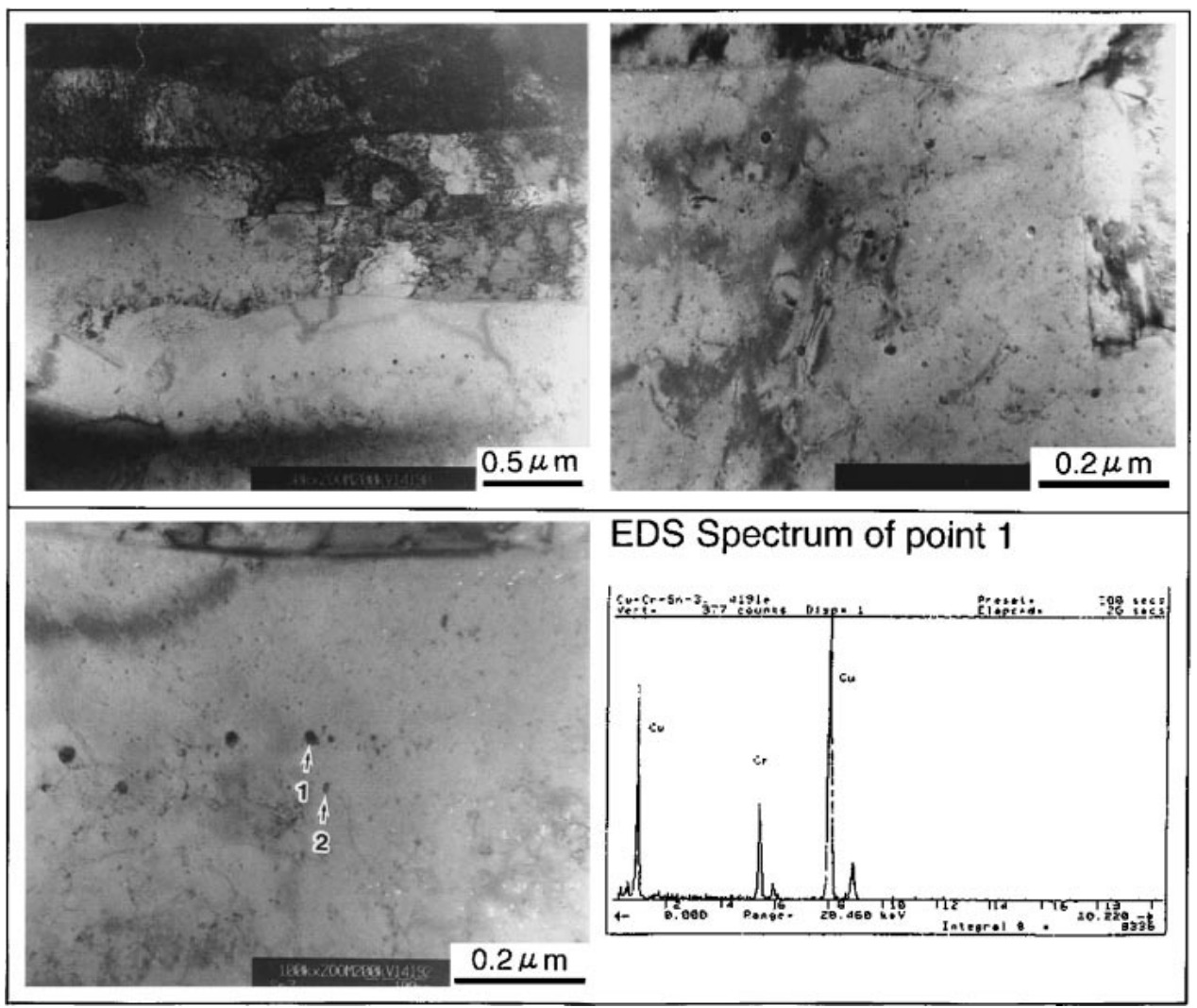

Fig. 12 TEM bright field images and EDS spectrum of the STCA specimen in $15 \mathrm{C} 1 \mathrm{~S}$ alloy. $\eta=5.3$ and aged at $873 \mathrm{~K}$ for $1 \mathrm{~h}$ (overaged condition). 


$$
\begin{aligned}
& \sigma_{\mathrm{C}}=\sigma_{\mathrm{T}}^{0}+k d^{-1 / 2} \\
& \sigma_{\mathrm{T}}^{0}=V_{\mathrm{Cu}}\left(\sigma_{\mathrm{Cu}}^{0}+A \varepsilon_{\mathrm{Cu}}^{n}\right)+V_{\mathrm{Cr}}\left(\sigma_{\mathrm{Cr}}^{0}+B \varepsilon_{\mathrm{Cr}}^{n}\right)
\end{aligned}
$$

Here, $V_{\mathrm{Cu}}, V_{\mathrm{Cr}}$ are volume fraction of each phase. $d$ is $\mathrm{Cr}$ lamellar spacing.

$A$ and $B$ are constant and $\mathrm{n}$ is strain hardening exponent. This equation has described well in the case of cold rolled specimens. However, it is necessary further to modify this equation in the case of cold rolled and aged specimens. Because, the precipitates nucleated on the vacancies and dislocations contributes to the strengthening to great extent as seen in Fig. 8, while work hardening term in the eq. (2) tends to decrease.

\subsection{The relation between the strength and hardness}

It is generally accepted the linear relation between the tensile strength (usually $0.2 \% \mathrm{PS}$ is also true) and hardness. Figures 13 and 14 show the results for STC and STCA specimens in the $15 \mathrm{C} 1 \mathrm{~S}, 15 \mathrm{C} 5 \mathrm{~S}$ and $15 \mathrm{Cr}$ alloys. If one pays

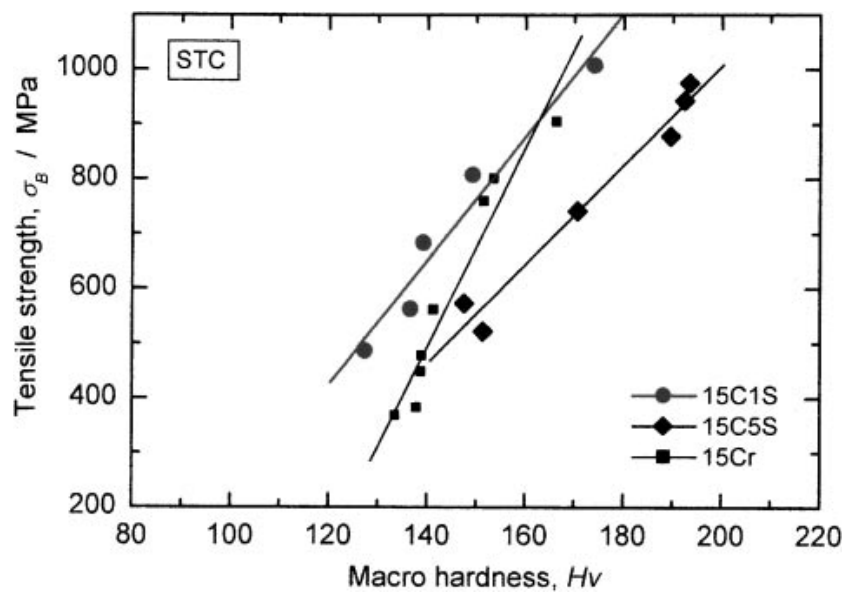

Fig. 13 Relation between tensile strength and macrohardness in the cold drawn $15 \mathrm{C} 1 \mathrm{~S}, 15 \mathrm{C} 5 \mathrm{~S}$ and $15 \mathrm{Cr}$ (STC specimens).

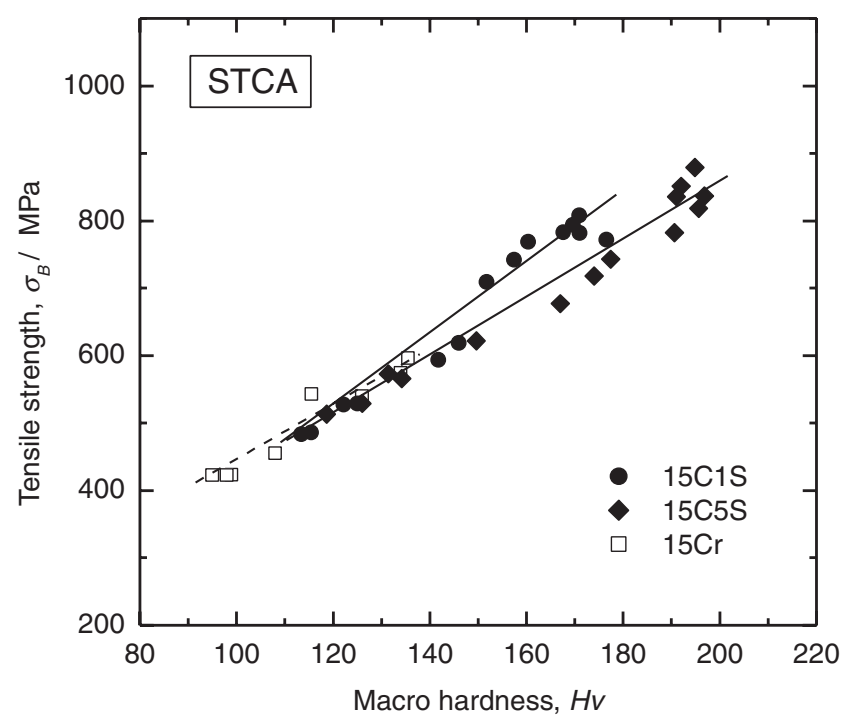

Fig. 14 Relation between tensile strength and macrohardness of STCA specimens in $15 \mathrm{C} 1 \mathrm{~S}, 15 \mathrm{C} 5 \mathrm{~S}$ and $15 \mathrm{Cr}$. Drawing strain is $\eta=5.3$ for $15 \mathrm{C} 1 \mathrm{~S}, 15 \mathrm{C} 5 \mathrm{~S}$ and $\eta=5$ for $15 \mathrm{Cr}$. attention to the data for STC of $15 \mathrm{C} 1 \mathrm{~S}$, tensile strength is given as a function of hardness as in the following: $\sigma_{\mathrm{B}}=11.3 \mathrm{Hv}-930$. From this figure and equation, the tensile strength of $\sigma_{\mathrm{B}}=1000 \mathrm{MPa}$ corresponds to $170 \mathrm{Hv}$. On the other hand, in the STCA specimens of $15 \mathrm{C} 1 \mathrm{~S}$, the tensile strength of $\sigma_{\mathrm{B}}=5.5 \mathrm{Hv}-150$ is derived. Tensile strength $\left(\sigma_{\mathrm{B}}\right)$ of STCA is less sensitive to the hardness, leading to the lower strength even having higher hardness for peak age hardened stage (Fig. 9). One of the reasons for this is that the cracking tendency becomes higher when tensile tested, resulted in the lower tensile strength due to the lower yield fracture.

Biselli $^{4)}$ is discussing the difference between the $0.2 \% \mathrm{PS}$ and tensile strength for tensile test and compression test to elucidate the elastic residual strain introduced by the heavy cold drawing in the in-situ composite $\mathrm{Cu}-\mathrm{Fe}$ alloy. It shows that $0.2 \% \mathrm{PS}$ in the tensile test is higher than that of compression test in the range of drawing strain less than 4.5 because of elastic residual strain (compression strain), but if the drawing strain is higher than 4.5 or at the tensile strength level, the difference becomes negligible small. This argument does not apply in the present case. If one can extrapolate Hv of the STCA data (Fig. 14) to STC result (Fig. 13), tensile strength of the STCA becomes $1000 \mathrm{MPa}$ for $15 \mathrm{C} 1 \mathrm{~S}$ and $1250 \mathrm{MPa}$ for $15 \mathrm{C} 5 \mathrm{~S}$ alloy. This point is meaningful to conduct further research.

\subsection{The relation between EC and tensile strength}

In order to see the optimum process condition giving the best combination of strength and EC, experimental data was summarized in Fig. 15 for the three alloys, 15C1S, 15C5S and $15 \mathrm{Cr}$. The region, where hardness over $160 \mathrm{Hv}$ corresponds to the tensile strength of more than $800 \mathrm{MPa}$ and EC over 70\%IACS, is the area of optimum processing condition. Best combination is cold drawing to $\eta=5.3$ and aging at $698 \mathrm{~K}$ for $1 \mathrm{~h}$ which gives $180 \mathrm{Hv}$ (tensile strength is $1100 \mathrm{MPa}$ ) and EC is $70 \% \mathrm{IACS}$ in $\mathrm{Cu}-15 \% \mathrm{Cr}-0.1 \% \mathrm{Sn}$ (15C1S).

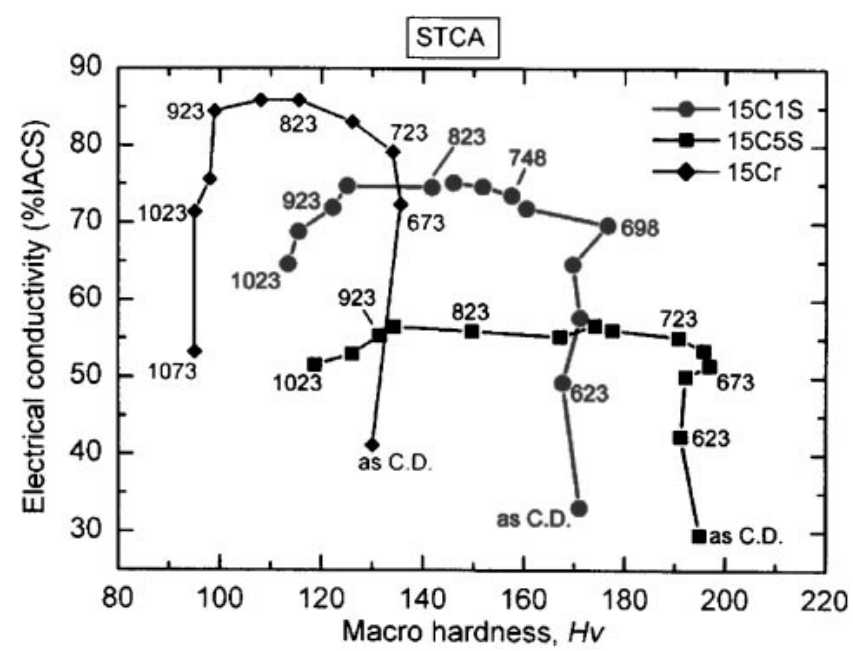

Fig. 15 Relation between electrical conductivity and macrohardness of STCA specimens in $15 \mathrm{C} 1 \mathrm{~S}, 15 \mathrm{C} 5 \mathrm{~S}$ and $15 \mathrm{Cr}$. Drawing strain is $\eta=5.3$ for $15 \mathrm{C} 1 \mathrm{~S}, 15 \mathrm{C} 5 \mathrm{~S}$ and $\eta=5$ for $15 \mathrm{Cr}$. The numerical numbers indicate aging temperatures in $\mathrm{K}$. 


\section{Conclusion}

Effect of Sn addition on the mechanical and electrical properties has been studied. Main results are as follows.

(1) $\mathrm{Sn}$ is effective to increase the strength of as-cold rolled as well as aged specimens in $\mathrm{Cu}-15 \% \mathrm{Cr}$ in-situ composites.

(2) Sn acts as a solid solution hardener and retards the dynamic recrystallization of $\mathrm{Cu}$ matrix, resulted in high density of dislocations and banded structure. The addition of $0.5 \% \mathrm{Sn}$ gives maximum tensile strength of $1000 \mathrm{MPa}$ in the cold rolled stage.

(3) $\mathrm{Sn}$ addition accelerates the precipitation of $\mathrm{Cr}$ in $\mathrm{Cu}$ matrix.

(4) Electrical conductivity decreases sharply with the addition of Sn.

(5) Optimum condition for having tensile strength of $1100 \mathrm{MPa}$ and electrical conductivity of $70 \%$ IACS is cold drawing $\eta=5.3$ and aging at $698 \mathrm{~K}$ for $1 \mathrm{~h}$ in the $\mathrm{Cu}-15 \% \mathrm{Cr}-0.1 \% \mathrm{Sn}$ in-situ composites.

\section{Acknowledgements}

Authors are indebted to Prof. M. Kato and his colleagues of Tokyo Institute of Technology for their stimulus discussions. The authors gratefully thank to the related members of NIMS, National Institute for Materials Science and NEDO, New Energy Development Organization of their financial support. This work was mainly done at NIMS under the contract with NEDO. They are also grateful to JSPS, Japan Science Promotion Society for her financial support of H. G. Suzuki's staying in Beijing. This work was partially done in
Tsinghua University, which faculty members are greatly appreciated.

\section{REFERENCES}

1) Y. Umakoshi, M. Yamaguchi, T. Kondo and G. Mima: J. Japan Inst. Metals 35 (1971) 223-230.

2) P. D. Funkenbusch, T. H. Courtney and D. G. Kubisch: Scr. Metall. 18 (1984) 1099-1104.

3) P. D. Funkenbusch and T. H. Courtney: Acta Metall. 33 (1985) 913922.

4) C. Biselli and D. G. Morris: Acta Metal. Mater. 42 (1994) 163-176.

5) T. Takeuchi, K. Togano, K. Inoue and H. Maeda: J. Less-Common Met. 157 (1990) 25-35.

6) G. Frommeyer and G. Wassermann: Acta Metall. 23 (1975) 13531360 .

7) G. Frommeyer: Phys. Chem. 82 (1978) 323-328.

8) Y. Sakai, K. Inoue, T. Asano, H. Wada and H. Maeda: Appl. Phys. Lett. 59 (1991) 2965-2967.

9) Y. Sakai, K. Inoue, T. Asano and H. Maeda: J. Japan Inst. Metals 55 (1991) 1382-1391.

10) J. D. Verhoeven, W. A. Spitzig, L. L. Jones, H. L. Downing, C. L. Trybus, E. D. Gibson, L. S. Chumbley, L. G. Fritzemeier and G. D. Schmittgrund: J. Mater. Eng. 12 (1990) 127-139.

11) K. Adachi, S. Tsubokawa, T. Takeuchi and H. G. Suzuki: J. Japan Inst. Metals 61 (1997) 397-403.

12) K. Mihara, T. Takeuchi and H. G. Suzuki: J. Japan Inst. Metals 62 (1998) 238-245.

13) K. Mihara, T. Takeuchi and H. G. Suzuki: J. Japan Inst. Metals 62 (1998) 599-606.

14) Y. Jin, K. Adachi, T. Takeuchi and H. G. Suzuki: Mater. Sci. Eng. A212 (1996) 149-156.

15) Y. Jin, K. Adachi, T. Takeuchi and H. G. Suzuki: Metal. Trans. A 29A (1998) 2195-2203.

16) T. B. Massalski: Binary Alloy Phase Diagram, 2nd ed.,Vol. 2 (1992) 1481, ASM Int.

17) S. Sun, S. Sakai and H. G. Suzuki: Mater. Trans. 42 (2001) 1007-1014. 